\title{
Research on technical solution of displacement and deformation monitoring of high-rise buildings in real time
}

\author{
Khai Cong Pham*
}

Faculty of Geomatics and Land administration, Hanoi University of Mining and Geology, Vietnam

\author{
ARTICLE INFO \\ Article history: \\ Received 01stFeb. 2020 \\ Revised 20th May 2020 \\ Accepted 30 $0^{\text {th }}$ June 2020 \\ Keywords: \\ Continuous Monitoring, \\ Continuously Operating \\ Reference Station (CORS), \\ Displacement and \\ Deformation, \\ Global Navigation Satellite \\ System (GNSS), \\ Net S8+receiver, \\ Real Time.
}

\begin{abstract}
This article presents a technical solution of displacement and deformation monitoring in real-time based on GNSSCORStechnology. The components and principles of operation of the monitoring system for displacement and deformation have been designed and established. The continuous operation reference station (CORS) with Net S8+ receiver was used to correct position for monitoring station in the RTCM format. A device for receiving and transmitting data from the monitoring station to the server has been designed and developed. NMEA messages have been decoded and filtered through three steps using our self-developed software which improves the accuracy of the monitoring results. The results of monitoring of displacement and deformation of An Binh high-rise building (in Hanoi) show that the developed equipment system can monitor displacement horizontally to $3 \mathrm{~mm}$ and vertical displacement to $5 \mathrm{~mm}$.
\end{abstract}

Copyright @ 2020 Hanoi University of Mining and Geology. All rights reserved.

\section{Introduction}

The industrialization and urbanization processes have occured fast during the last several decades which lead to industrial and civil construction projects that are getting bigger and higher. However, the construction works on the ground are often displaced and deformed due to the impact of many different factors, therefore, monitoring displacement and deformation of

${ }^{*}$ Corresponding author

E-mail: phamcongkhai@humg.edu.vn

DOI: 10.46326/ JMES.2020.61(3).09 construction works is an important task. The real time identification of the deformation and displacement of buildings can reduce the risk of accidents that can happen to people and avoid financial losses (Bochen Zhang et al., 2018; Deng Hui Wang et al., 2017). Up to now in Vietnam most of the deformation and displacement monitoring works are mainly periodically carried out by traditional measuring devices such as level, theodolite, total electronic station or by GPS technology. It is difficult to monitor continuously changing deformation and displacement in real time by using this technology and equipments.

The deformation and displacement surveying needs to be automatically and 
continuously carried out in real time due to the rapid development of new technology. The deformation and displacement surveying of high-rise buildings has been effectively studied by GNSS technology (N. Quesada-Olmo et al., 2018; Wan Abdul Aziz Wan Mohd Akib et al., 2012). Deflection and horizontal displacement of bridges can be determined by using GNSS technology (Jiayong Yu et al., 2014). The GNSS system currently allows the continuous reception of satellite signals using real-time RTK dynamic measurement technology with high accuracy. The advantages of GNSS technology are to provide 3D data in real time, operate continuously with different weather conditions, the position with high precision, therefore, this technology has been applied to survey displacement and deformation of bridges effectively (Ruijie Xi et al., 2018).

The GNSS technology monitoring system has been widely and effectively applied in many countries over the world. However, these systems all have their own hardware, software and high cost. Therefore, the idea of developing a system for real time continuously monitoring deformation transformation based on GNSS/ CORS technology has been proposed. From the working principle and data transmission mechanism of CORS station with Net S8+receiver, this article describes the development of a device to receive and transmit the corrected data from the user station (User) located at the monitoring position to master station (Server). All measurements from the user station are automatically and continuously sent to the master station. Here software (Server GNSS CORS WDM, GNSS CORS WDM (Pham Cong Khai et al., 2019, Pham Cong Khai et al., 2020) have been designed to handle the measured data received from the user at the monitoring point to produce the results of the instantaneous displacement and deformation of the construction works. To test the accuracy and stability of the system, a dedicated device has been designed and assembled. The results of experiments show that the monitoring system works properly, stably, continuously 24/ 7 and can monitor the deformation and displacement of the construction works (An Binh high-rise building) from $3 \mathrm{~mm}$ upwards.

\section{General principles of deformation and displacement monitoring work}

The monitoring of deformation and displacement of construction works is the essential determination of its position change in space over a period of time. The equation for calculating displacement and deformation of construction works is shown in the following formula (Hepi Hapsari Handayani et al., 2015).

$\mathrm{dp}=\mathrm{R}^{\prime} \mathrm{p}-\mathrm{Rp}=\mathrm{dp}(\mathrm{Xp}, \mathrm{Yp}, \mathrm{Hp}, \mathrm{t})$

Where:

$\mathrm{Rp}$ - position of $\mathrm{P}$ point at time $\mathrm{t}=0$ (before deformation);

R'p - position of $\mathrm{P}$ point at time $\mathrm{t}>0$ (after deformation).

The deformation and displacement quantity in formula (1) is defined in 4-dimensional space, including 3 dimensions according to component coordinates $\mathrm{X}, \mathrm{Y}, \mathrm{H}$, and the fourth one is time $\mathrm{t}$. The deformation along each coordinate axe is determined by the following formulas:

- Deformation along $X: D x=X_{i}(t+1)-X_{i}(t)$

- Deformation along Y: Dy $=Y_{i}(t+1)-Y_{i}(t)$

- Fully deformation: $D p=\sqrt{D x^{2}+D y^{2}}$

-Vertical deformation (settlement): $\eta=\mathrm{H}_{\mathrm{i}}$ $(\mathrm{t}+1)-\mathrm{H}_{\mathrm{i}}(\mathrm{t})$

Where: $\mathrm{X}_{\mathrm{i}}(\mathrm{t}), \mathrm{Y}_{\mathrm{i}}(\mathrm{t}), \mathrm{H}_{\mathrm{i}}(\mathrm{t})$ are the coordinates of the $i^{\text {th }}$ point at time $t$ (before deformation).

$\mathrm{X}_{\mathrm{i}}(\mathrm{t}+1), \mathrm{Y}_{\mathrm{i}}(\mathrm{t}+1), \mathrm{H}_{\mathrm{i}}(\mathrm{t}+1)$ are the coordinates of the ith point at time $(t+1)$ (after the deformation).

Thus, the nature of the deformation and displacement determination is to determine the coordinates of the monitoring points attached to the building at different times. Real-time monitoring of deformation and displacement is to continuously and instantaneously determine the coordinates of the monitoring points. This process is performed by a technical solution based on GNSS/ CORS technology.

3. The components and operation principles of the system for real time monitoring of deformation and displacement of construction works

\subsection{Components of the monitoring system}




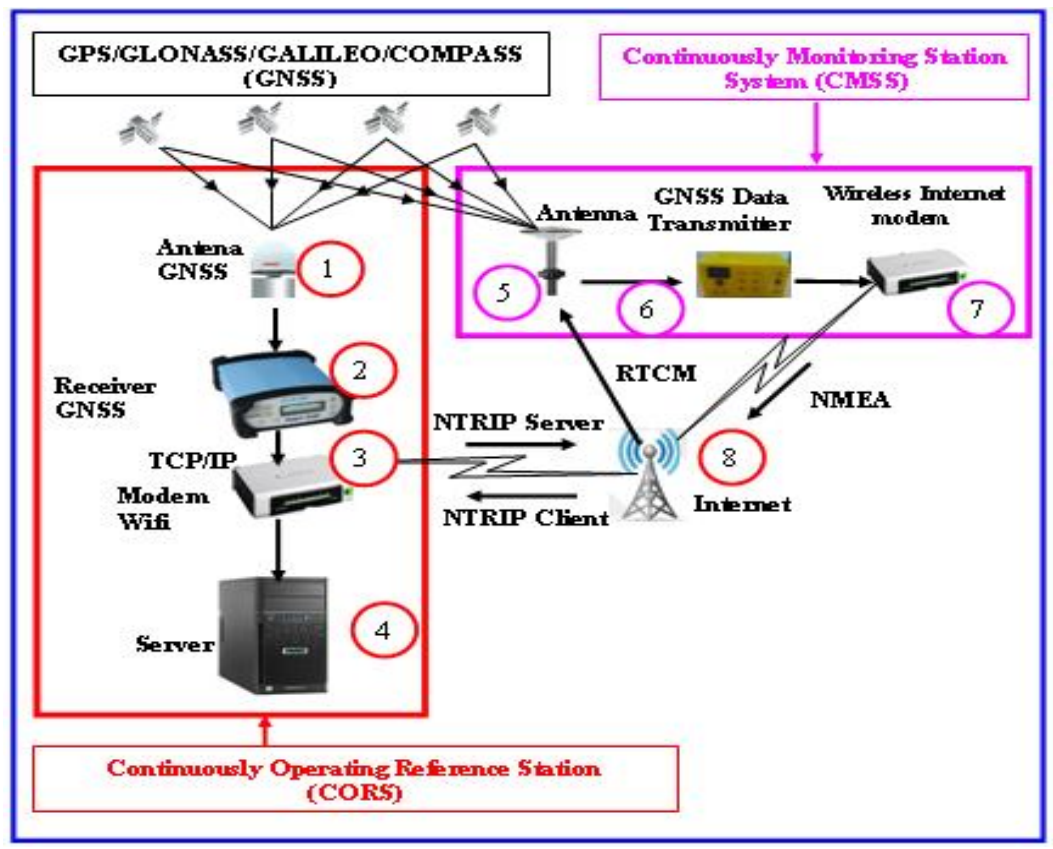

Figure 1. Diagram of real time displacement and deformation monitoring system.

The real time deformation monitoring system is developed based on GNSS/CORS technology. The whole system consists of two parts. The first part is the Continuously Operating Reference Station system (CORS), and the second part is the Continuously Monitoring Station System (CMSS) (Figure 1).

The set up CORS station system consists of two basic parts, such as hardware and software. Hardware includes GNSS antenna (1), GNSS Net S8+receiver (2), modem and internet connection (3), and host computer (4). Software for controlling CORS stations include station management software (NRS-Station) and user management software (NRS-Server).

The Continuously Monitoring Station System also includes hardware and software. The hardware includes an antenna that receives GNSS satellite signals (5), GNSS data acquisition and transmission equipment (6), modem (7) and wireless internet connection (8). Our selfdeveloped software includes 1) software to receive and transmit GNSS data from the monitoring station to master station (Server GNSS CORS WDM) and 2) software for processing monitored data to calculate deformation and displacement of construction works (GNSS CORS WDM).

\subsection{Principle of operation of the monitoring system}

The operating principle of the continuous monitoring station system is based on the operation principle of the GNSS/ CORS system. The GNSS satellite signals are received by the antenna (1), transmitted to the GNSS Net S8+ receiver via a dedicated cable, where the satellite signals are decoded and passed through the modem (3) to the host computer (4). Through the host computer, which is connected to the internet with a static IP address, it is possible to decentralize management depending on each user with two accompanying software: NRS Station (for calculation of data and distribution of static station data) and NRS-Server that provides differential corrections for mobile measuring points, processes data of RTK network, estimates ambiguities of the whole network, sets up processing options (including tropospheric model, the ionospheric effect, and the satellite orbit). Data in CORS station is continuously collected every 1 second, 15 seconds or 30 seconds, depending on user requirements, and is set up in NRS-Station software. The data is stored in a certain directory in the server according to the format of the RINEX file. 
The deformation and displacement monitoring of construction works are implemented by the method of GNSS/ CORS/ RTK. The user is a multifrequency GNSS receiver with a telephone Sim slot located at the monitoring station, connected to the CORS station and it will send the approximate coordinates to the master station through a series of measurement data with NMEA's standard data format (National Marine Electronics Association) of the National Marine Electronics Association (Kai Shi et al., 2017).

The measured data from rovers are sent to the master station according to the NMEA (National Marine Electronics Association) data format of the National Marine Electronics Association (USA).

At the server, NRS-Server software will calculate and determine the number of corrections for the user and exactly determine the coordinates for the user and transmit in RTCM data format and stored in the manual of the user.

\section{Design and development of GNSS data acquisition and transmission equipment}

\subsection{Design of hardware system}

Receiving and transmitting data from the monitoring station to CORS station are continuously carried out to provide the spatial position of the monitoring point in real time. The GNSS data acquisition and transmission equipment, which includes the main modules, as follows, is designed and developed by us.

\subsubsection{Signal acquisition module Max232}

The Max232 signal acquisition module is device for transferring the RS232 signal (Recommended Standard 232) into the TTL logic signal (Transistor-Transistor Logic), which is able to create communication between RS232 standard devices and TTL standard devices. Characteristics of the module are highly accurate, reliable in data preservation, with high processing speed, small power consumption, and signal delay.

\subsubsection{Module for data processing Arduino UNO R3}

This is a central control module that controls the operation of other modules and codes are directly loaded on the ATmega 328 microprocessor. In signal transmission protocols, the ATmega328 is responsible for receiving data and returning them to other modules, from here, the data forms continuous and interdependent connections.

The module is designed with 7 analog pins, 13 digital pins, and 6/13 integrated digital pins. Board runs in direct DC voltage range from $7 \mathrm{~V}$ to $20 \mathrm{~V}$, a new type of ATmega 328 chip, AVR family, operates the 8-bit platform, $5 \mathrm{~V}$ voltage, $0.2 \mathrm{~mA}$ current, and all boards have a level power consumption of $2.5 \mathrm{~W}$.

\subsubsection{Ethernet W5100 module for data storage and} data transmission to server

This is a transmission system as well as a data storage system. Module integrated to Ethernet W5100 processor chip can give a LAN network transfer rate up to $100 \mathrm{Mbps}$. It is additionally integrated to Micro SD memory card in up to $4 \mathrm{~Gb}$ capacity.

The module also integrates status indicating lights including LAN, Full, RX, TX, ... to make the error control more flexible.

\subsubsection{Real time module}

Real time module supplies the real time for Arduino to determine the time that data is transferred from Rover station to CORS station. The real time module is periodically calibrated to the satellite time to always ensures the accuracy required for all activities on the Rover system. The real time module connects directly with Arduino using IC2s standard with analog 5 or analog 6 pin. The module is directly powered by $5 \mathrm{~V}$ from Board Arduino.

\subsubsection{Internet signal transmission system}

This is a signal transmission tool from Rover to CORS station and vice versa. In the CORS modem, the modem is integrated and additionally supported by output ports to create signal paths via wireless internet. This port is fixed with a static IP address provided by the network.

All the above modules are integral to create a GNSS data acquisition and transmission unit from the monitoring station to the CORS station management server. This device is called GNSS Data Transmitter (Figure 2). 


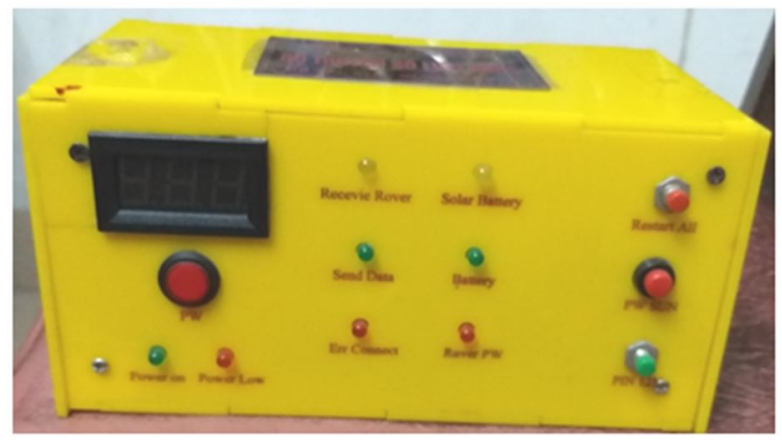

a) Front

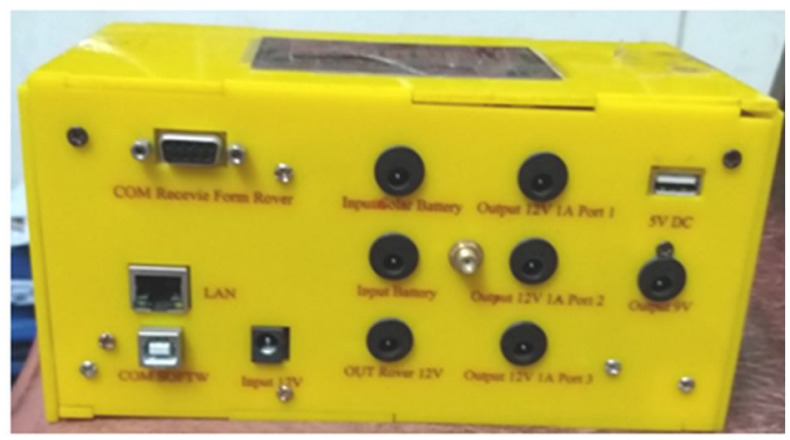

b) Behind

Figure 2. GNSS data receiver and transmission device.

\subsection{Design and construction of system control software}

After a GNSS data acquisition and transmission devices have been designed and installed, controlling software has been designed and built. They are written in NMEA's standard data format using the Arduino programming tool and the C\# programming language.

When software source code has been written and checked for errors, it is loaded into the GNSS data transmitter via the USB connector to the computer by Arduino's programming tool.

The satellite signal collected from Rover in NMEA standard format is directly transmitted to Arduino via RS232 port.

The received Arduino signals are divided into two types \$GPGGA, \$GNGGA, and other NMEA signals.

The \$GNGGA signals are transmitted to the Server according to NTRIP server protocol, and other NMEA signals are simultaneously transmitted to Ethernet W5100 and stored in the SD memory card that is integrated into Ethernet W5100 in the text file format.

The \$GNGGA signals are processed, and the results are sent to the software in the server to provide instant location.

These data are automatically processed by our self-developed software (GNSS CORS WDM), and deformation and displacement quantities are determined with the highest accuracy.

\section{Decoding the GNSS data structure in NMEA format}

The data structure in the NMEA format is a technical standard that allows electronic devices to send information to computers and to another electronic device (Pham Cong Khai et al., 2019). The standard was developed by the National Marine Electronics Association (NMEA). NMEA data structure has many versions currently but NMEA 0183 version is widely used with ASCII standard code.

The electrical standard used is EIA-232. Most of the hardware allows format with the NMEA0183 via EIA-232 port. In order to set up a program that controls satellite signal transmission and acquisition deceive, it is necessary to have standard information about the format structure of this data standard. Figure 3 displays the GNSS data structure according to the NMEA 0183 format standard of some types of messages returned by Rover.

Each NMEA format code starts with a "\$" character on a serial row and cannot consist of more than 80 characters. The data is displayed on a row with different types and separated by commas (,), after a comma is space characters. Data streams are commonly GNGSA, GNRMC, GNVTG, GNGGA, GNGLL, GNGSV, GNZDA, and then are information about time, coordinates, status, and altitude. Figure 3 presents some data codes according to the NMEA format standard obtained from GNSS receivers.

All these data have been decoded in order to filter out the highest-quality GNSS measurement information especially two types of \$GNGGA, and \$GNGSV messages are paid attention. The GNGGA message line indicates which measurements meet the accuracy requirement (Fixed solution) and 


\begin{tabular}{|l|}
\hline \$GNGGA,hhmmss.ss,llll.lll,a,yyyyy.yyy,a,x,uu,v.v,w.w,M,x.x,M,,zzzz ${ }^{*} \mathrm{hh}<\mathrm{CR}><\mathrm{LF}>$ \\
\hline \$GNGLL,llll.lll,a,yyyyy.yyy,b,hhmmss.sss,A,a*hh $<\mathrm{CR}><\mathrm{LF}>$ \\
\hline \$GNGSA,a,x,xx,xx,xx,xx,xx,xx,xx,xx,xx,xx,xx,xx,u.u,v.v,z.z*hh $<\mathrm{CR}><\mathrm{LF}>$ \\
\hline \$GNGSV,x,u,xx,uu,vv,zzz,ss,uu,vv,zzz,ss,...,uu,vv,zzz,ss*hh $<\mathrm{CR}><\mathrm{LF}>$ \\
\hline \$GNRMC,hhmmss.sss,x,llll.lll,a,yyyyy.yyy,a,x.x,u.u,xxxxxx,,,v*hh<CR $><\mathrm{LF}>$ \\
\hline \$GNVTG,x.x,T,y.y,M,u.u,N,v.v,K,m*hh<CR $><\mathrm{LF}>$ \\
\hline \$GNZDA,hhmmss.sss,dd,mm,yyyy,xx,yy*hh<CR $><\mathrm{LF}>$
\end{tabular}

Figure 3. Some data codes according to NMEA 0183 format standard.

the GNGSV message line indicates the positional uncertainty of Fixed points.

All measurements reached required accuracy are stored in daily files, and these files have names associated with measured dates (e.g. data25082018.txt). These data files are processed by (GNSS CORSWDM) software to give real-time results about deformation and displacement.

\section{Building software to receive and process deformation and displacement monitoring data}

Deformation and displacement monitoring data of construction works are continuously transmitted from the monitoring station to the host computer (Server) through the data transmission unit. There is two software designed to ensure that the monitoring station system can continuously work without being conflicted with data. The first software (Server GNSSCORSWDM) has the function of receiving data from the rovers at the monitoring point and sending them to the server (Figure 4a). The second software (GNSS CORS WDM) has the function of analyzing and processing data received from the first software to get the most accurate result file and to identify and display the deformation and displacement quantities. Software for analyzing and processing deformation and displacement monitoring data of construction works is written in VB.Net programming language by Visual Studio 2017 programming tool. The interface of the software can be seen in Figure $4 b$.

\section{Experiment and Results}

7.1. Designing and building of equipment system for real-time and accurate monitoring of deformation and displacement of construction works
The equipment system is designed and manufactured, including a horizontal rail attached with a steel ruler to determine horizontal displacement. The monitoring mark is attached to 4 wheels to be able to move on the rail. The monitoring mark is attached to a vertical steel ruler to monitor vertical displacement. The monitoring device consists of a GNSS Net S8+ receiver supplied by South Company, GNSS data acquisition and transmission equipment, wireless internet modem, battery, and solar battery. The GNSS receiver is fixed to the monitoring mark, the receiver is activated, and the monitoring device is connected to the receiver via Bluetooth. The system will automatically receive and transmit data to the server. The indication lights will show the operating status of the monitoring station system.

\subsection{Processing monitored data}

Experiments for real-time monitoring of deformation and displacement of construction works were performed in four different periods of time on 20,22, 24, 26 of August 2018 on An Binh building in Hanoi. With each monitoring point the signals are collected every hour when the monitoring point is moved over a certain distance. The deformation and displacement quantities of this monitoring point are determined and based on the steel ruler attached to the monitoring mark (this quantity is used for checking). From the monitoring data the deformation and displacement quantities can be determined by CORS/ RTK measuring technique.

Data collected at the NMEA 183 standard monitoring station is continuously sent from the monitoring station to the server with a frequency of 1 message per second. Figure 5 shows a segment of the data file according to the NMEA 
a)

Server GNSS CORS WDM

Tệp Cài iặt Các Tiện Ích Thông tin

Cài đọ̆t Rover

Cổng

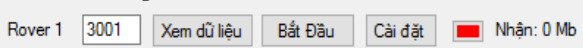

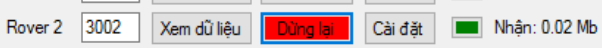

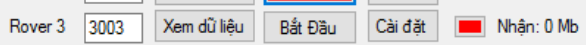

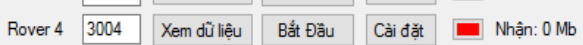

\begin{tabular}{ll|l|l|l|l|l|l|l} 
Rover 5 & 3005 & Xem dư liệu & Bát Đầu & Cài đặt \\
& Nhận: 0 Mb
\end{tabular}

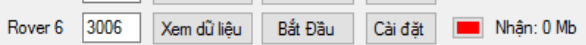

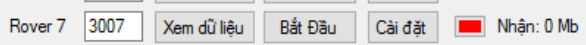

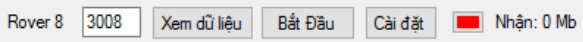

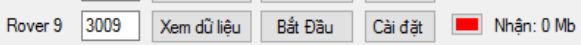

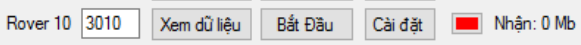

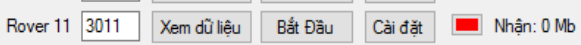

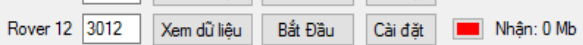

\begin{tabular}{|c|c|c|c|c|c|c|}
\hline \multicolumn{7}{|c|}{ ặt Rover } \\
\hline Rover 13 & 3013 & Xem dû liệu & Bắt Đâu & Cài đặt & $\square$ & Nhận: 0 Mb \\
\hline ver 14 & 3014 & Xem dû liệu & Bắt Đầu & Cài đặt & $\square$ & Nhận: 0 Mb \\
\hline ver 15 & 3015 & Xem dû liệu & Bất Đầu & Cài đặt & $\square$ & Nhận: 0 Mb \\
\hline Rover 16 & 3016 & Xem dû̉ liệt & Bắt Đầu & Cài đọ̆t & 口 & Nhận: 0 Mb \\
\hline ver 17 & 3017 & Xem dû́ li & Bắt Đầu & Cài đặt & 口 & Nhận: 0 Mb \\
\hline ver 18 & 3018 & Xem dû liệu & Bắt Đầu & Cài đọ̆t & $\square$ & Nhận: 0 Mb \\
\hline ver 19 & 3019 & Xem dũ liệt & Bắt Đầu & Cài đặt & $\square$ & Nhận: 0 Mb \\
\hline ver 20 & 3020 & Xem dũ lié & Bắt Đầu & Cài đọ̆t & 口 & Nhận: 0 Mb \\
\hline ver 21 & 3021 & Xem dû̀ & Bắt Đầu & Cà̀ đặt & 口 & Nhận: 0 Mb \\
\hline ver 22 & 3022 & Xem dũ & Bá & Cài đọ̆t & 口 & Nhận: 0 Mb \\
\hline er 23 & 3023 & Xem dû iệu & Bắt Đầu & Cài đặt & 口 & Nhận: 0 Mb \\
\hline ver 24 & 3024 & Xem dû liệu & Bắt Đầ & Cài đặt & $\square$ & Nhận: 0 Mb \\
\hline
\end{tabular}

b)

몸 GNSS CORS WDM

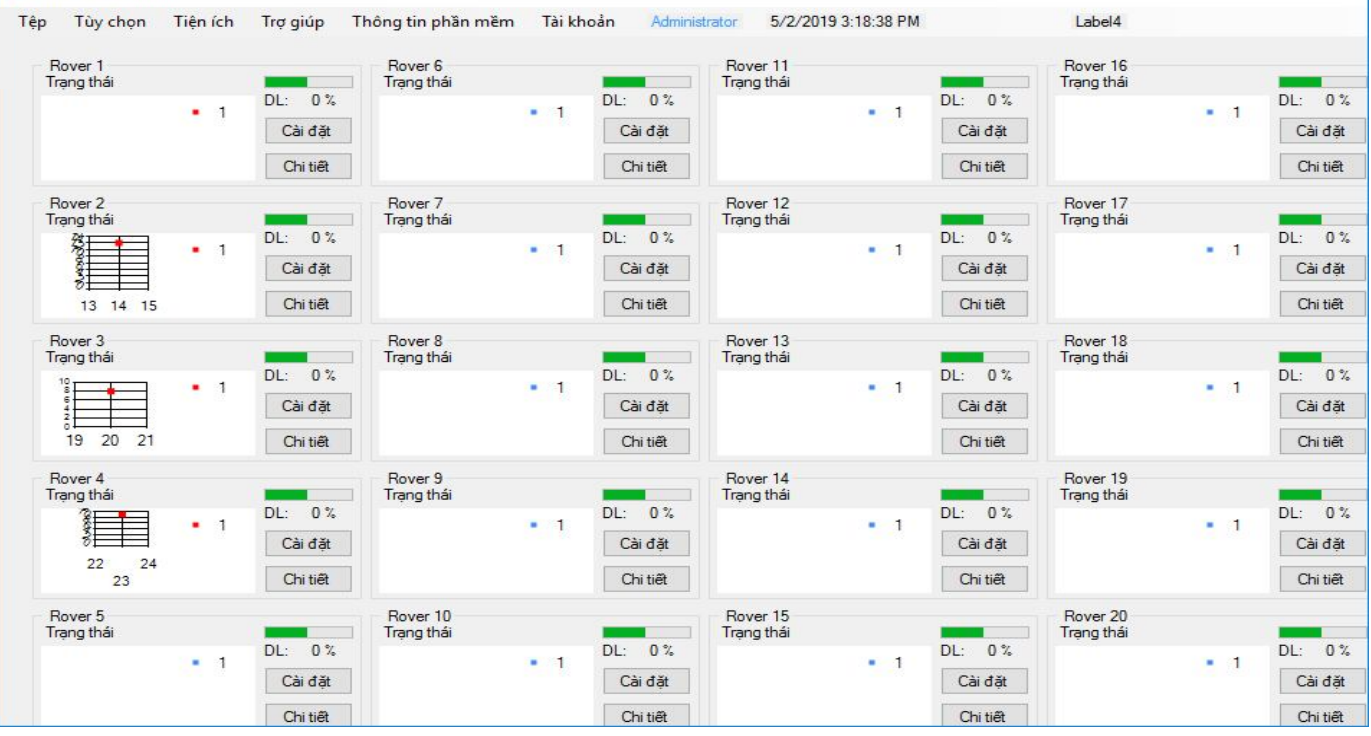

Figure. 4. Interface of

a) Server GNSSCORS WDM Software;

b) GNSS CORS WDM Software.

\begin{tabular}{|l|}
\hline \$GNGGK,164713.00,082518,2104.3054650,N,10546.4090182,E,1,23,1.7,EHT-1.331,M*72 \\
\hline \$PTNL,GGK,164713.00,082518,2104.3054650,N,10546.4090182,E,1,23,1.1,EHT-1.331,M*57 \\
\hline \$GNGGQ,164713.00,082518,2104.3054650,N,10546.4090182,E,1,23,1.000,-1.331,M*36 \\
\hline \$GNGLL,2104.3054650,N,10546.4090182,E,164713.00,A,A*77 \\
\hline \$GNGNS,164713.00,2104.3054650,N,10546.4090182,E,AANA,23,0.6,-1.331,,*63 \\
\hline \$GNGSA,A,3,03,10,14,16,22,26,29,31,,,1.1,0.6,0.9*2E \\
\hline \$GNGSA,A,3,70,71,73,80,,,,,,1.1,0.6,0.9*2E \\
\hline \$GPGSV,3,1,10,03,12,320,41,10,28,166,44,14,57,029,49,16,37,203,46*75 \\
\hline \$GPGSV,3,2,10,22,30,307,46,25,16,038,,26,69,200,51,29,14,084,41*7D \\
\hline \$GPGSV,3,3,10,31,50,356,51,32,51,077,50,,,,,*7B \\
\hline \$GLGSV,1,1,04,70,68,348,45,71,17,333,43,73,49,267,50,80,45,003,45*66 \\
\hline \$GAGSV,2,1,06,04,48,123,49,05,21,322,43,09,70,352,52,24,59,251,51*6F \\
\hline
\end{tabular}

Figure 5. NMEA data collected at the monitoring station on August 20, 2018.

standard collected at the monitoring station starting at 16:47:13, August 20, 2018.
From data file, in NMEA standard data format GPGGA, and GPGST messages are filtered 


\begin{tabular}{|c|}
\hline$\$$ GNGGA, $070309.00,2104.29999960, \mathrm{~N}, 10546.41406609, \mathrm{E}, 4,22,0.7,23.698, \mathrm{M},-28.333, \mathrm{M}, 1.0,4095^{*} 4 \mathrm{C}$ \\
\hline$\$$ SGNGGA,070310.00,2104.30000020,N,10546.41406564,E,4,22,0.7,23.699,M,-28.333,M,1.0,4095*41 \\
\hline \$GNGGA,070311.00,2104.29999998,N,10546.41406593,E,4,22,0.7,23.703,M,-28.333,M,1.0,4095*41 \\
\hline $2,0.7,23.700, \mathrm{M},-$ \\
\hline $46.41406699, \mathrm{E}, 4,22,0.7,23.701, \mathrm{M},-2$ \\
\hline $737, \mathrm{E}, 4,22,0.7,23.7$ \\
\hline $15.00,2104.30000032, \mathrm{~N}, 10546.41406652, \mathrm{E}, 4,22,0.7,23.689, \mathrm{M},-28.333, \mathrm{M}, 1.0$, \\
\hline \$GNGGA,070316.00,2104.29999938,N,10546.41406966,E,4,22,0.7,23.699,M,-28.33 \\
\hline$\$$ GGNGA, $070317.00,2104.29999921, \mathrm{~N}, 10546.41406725, \mathrm{E}, 4,22,0.7,23.698, \mathrm{M},-28.333, \mathrm{M}, 1.0,4095^{*} 49$ \\
\hline \$GNGGA,070318.00,2104.29999947,N,10546.41406839,E,4,22,0.7,23.701,M,-28.333,M,1.0,4095*45 \\
\hline \$GNGGA,070319.00,2104.29999955,N,10546.41406849,E,4,22,0.7,23.696,M,-28.333,M,1.0,4095*4F \\
\hline \$GNGGA, $070320.00,2104.29999779, \mathrm{~N}, 10546.41406726, \mathrm{E}, 4,22,0.7,23.699, \mathrm{M},-28.333, \mathrm{M}, 1.0,4095^{*} 4 \mathrm{C}$ \\
\hline \\
\hline
\end{tabular}

Figure 6. GNGGA data according to NMEA 0183 format standard

to get the best positions. The analyzing process is carried out in the following 3 steps:

Firstly, check the integrity of the messages in the NMEA data file.

After receiving messages in NMEA format from Rover, it is necessary to check the integrity of the messages in this data file, if the messages do not have sufficient information, they cannot be used. The integrity check of data is done by analyzing all characters in the range from $\$$ to $*$ of the NMEA message.

Secondly, filter the messages coordinates on which they are fixed.

In the GNGGA or GPGGA message sequence, if after the letter " $\mathrm{E}$ " there is number 4, these messages are good. If there is the number 0,1 , 2,3 , or 5 , these ones are not taken. Figure 6 shows a filtered message segment as an example.

Thirdly, choose messages from step 2 but having the smallest positional uncertainties. Filtering out coordinates with positional uncertainties is done by analyzing the GPGST or GNGST message sequence.

The average coordinate is calculated from those that have been filtered out over a monitoring period. Then the displacement of the building in the horizontal plane between the two monitoring times is determined through the coordinate $(\mathrm{X}, \mathrm{Y})$.

For example with monitoring data of 20/8/2018, horizontal displacement components can be determined as follows:

- Displacement by OX axis:
$\mathrm{Qx}=\mathrm{X}_{\mathrm{i}+1}-\mathrm{X}_{\mathrm{i}}=2330973.6773-2330973.6302$ $=0.0471 \mathrm{~m}$

- Displacement by OY axis:

Qy $=Y_{i+1}-Y_{i}=580383.4861-580383.4816=$ $0.0045 \mathrm{~m}$

-Complete translation:

$\mathrm{Q}=\sqrt{\mathrm{Q}_{\mathrm{X}}^{2}+\mathrm{Q}_{\mathrm{Y}}^{2}}=\sqrt{0.0471^{2}+0.0045^{2}}=0.0473 \mathrm{~m}$ $=47.3 \mathrm{~mm}$

-Vertical displacement:

$\eta=\mathrm{H}_{\mathrm{i}+1}-\mathrm{H}_{\mathrm{i}}=23.651-23.690=39 \mathrm{~mm}$

Table 1 displays the horizontal and vertical displacement values determined by monitoring equipment and directly measured by a steel ruler mounted on the monitoring mark, the maximum horizontal displacement is $2.3 \mathrm{~mm}$ and the minimum is $1.5 \mathrm{~mm}$.

The maximum vertical displacement is $4.2 \mathrm{~mm}$ and the minimum is $3.5 \mathrm{~mm}$.

\subsection{Experimental monitoring high-rise buildings}

Using the equipment system that has been studied and developed (7.1, 7.2 sections), the monitoring experiments are conducted at the An Binh high-rise building in Hanoi, Vietnam. The building has 24 storeys, 1 basement and 3 floors of commercial services. On the roof of the building, there are 04 corner observation stations with 4 Rover numbered Rover-01, Rover-02, Rover-03, and Rover-04 (Figure 7).

CORS station named CORS-N001 is used for monitoring which is built on the campus of Hanoi University of Mining and Geology, $2 \mathrm{~km}$ away from the building (Figure 8). 

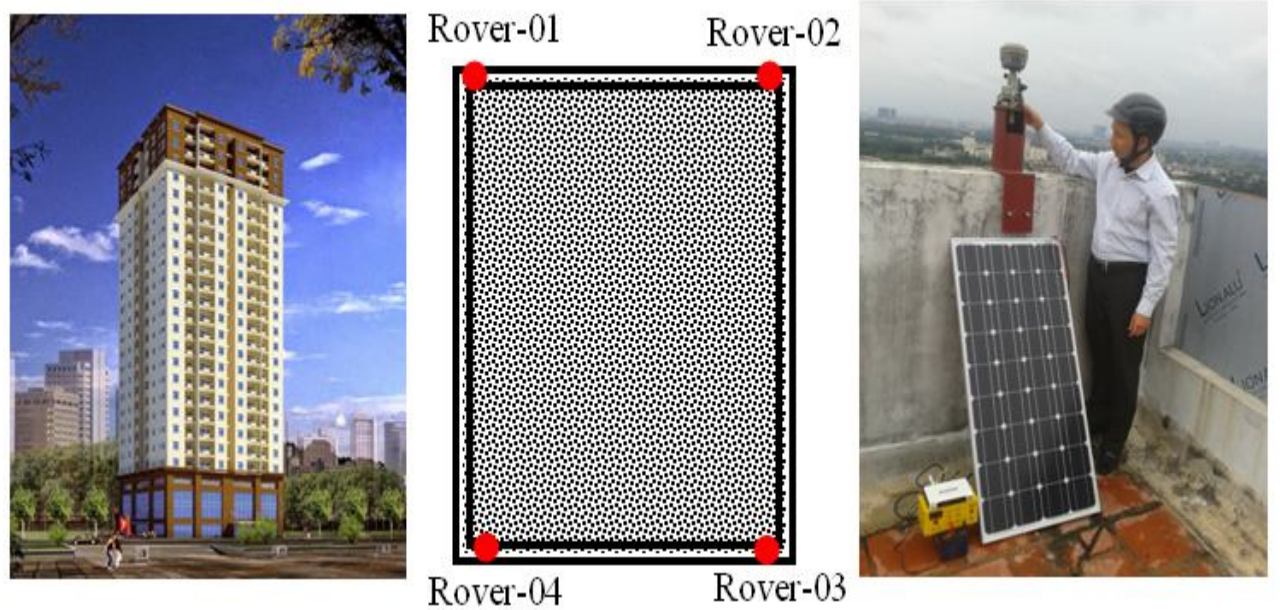

Figure 7. Experimental monitoring high-rise buildings.

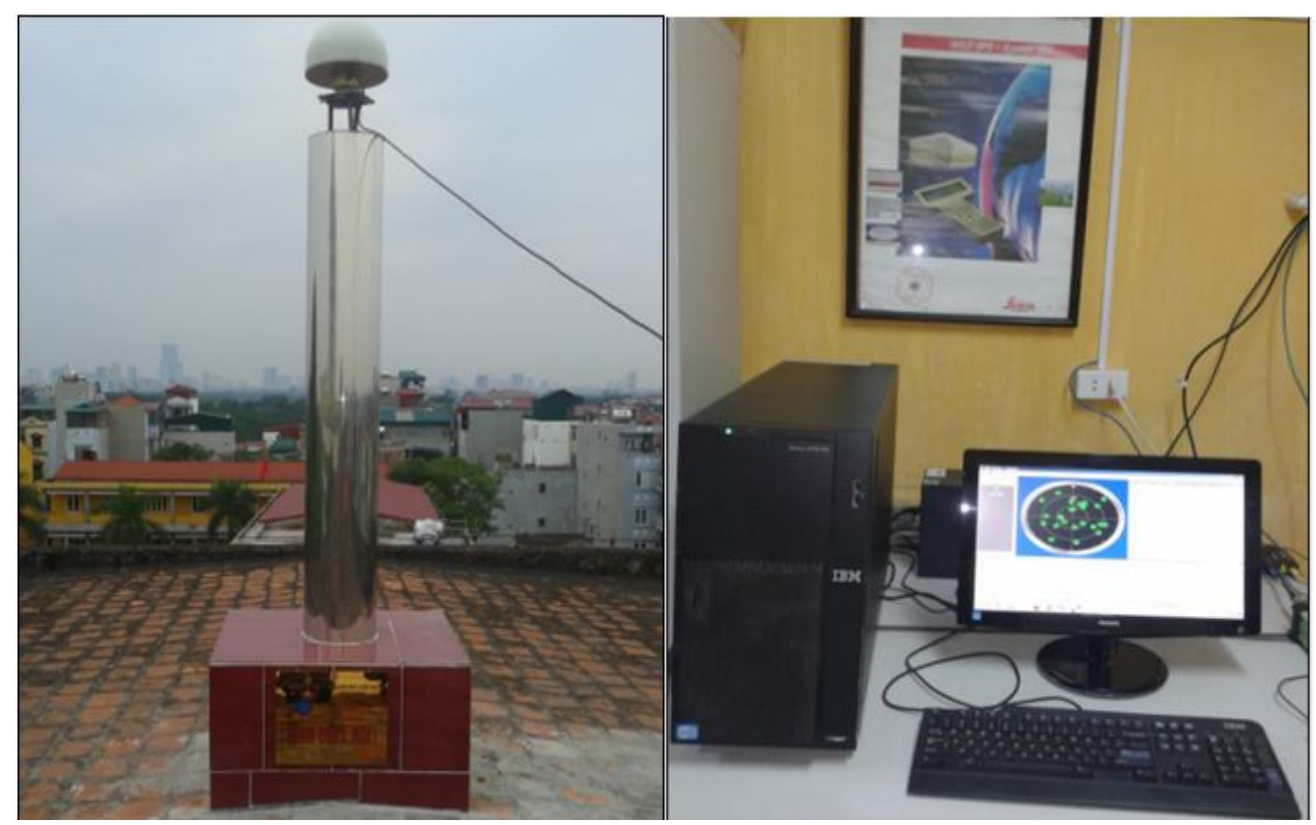

Figure 8. Installation of CORS N001 station system at Hanoi University of Mining and Geology.

Table 1. Evaluation of accuracy of horizontal and vertical displacement monitoring results.

\begin{tabular}{|c|c|c|c|c|c|c|}
\hline \multirow{2}{*}{$\begin{array}{c}\text { Number of } \\
\text { Observation }\end{array}$} & \multicolumn{3}{|c|}{ Horizontal displacement $(\mathrm{mm})$} & \multicolumn{3}{c|}{ Vertical displacement (mm) } \\
\cline { 2 - 7 } & $\begin{array}{c}\text { Measured } \\
\text { by a steel } \\
\text { ruler }\end{array}$ & $\begin{array}{c}\text { Observed } \\
\text { by CMSS } \\
\text { equipment }\end{array}$ & $\begin{array}{c}\text { Observed } \\
- \\
\text { Measured }\end{array}$ & $\begin{array}{c}\text { Measured } \\
\text { by a steel } \\
\text { ruler }\end{array}$ & $\begin{array}{c}\text { Observed } \\
\text { by CMSS } \\
\text { equipment }\end{array}$ & $\begin{array}{c}\text { Observed } \\
\text { Measured }\end{array}$ \\
\hline 1 & 45 & 47.3 & 2.3 & 35 & 39.0 & 4.0 \\
\hline 2 & 50 & 51.5 & 1.5 & 45 & 49.2 & 4.2 \\
\hline 3 & 55 & 53.2 & 1.8 & 55 & 58.5 & 3.5 \\
\hline 4 & 60 & 57.8 & 2.2 & 65 & 68.7 & 3.7 \\
\hline
\end{tabular}

After installing monitoring stations on the roof of the building, monitoring is automatically performed. Data at the monitoring stations were continuously sent to the server in the NMEA standard format every second. The data is saved to the server by the default path and file name. 


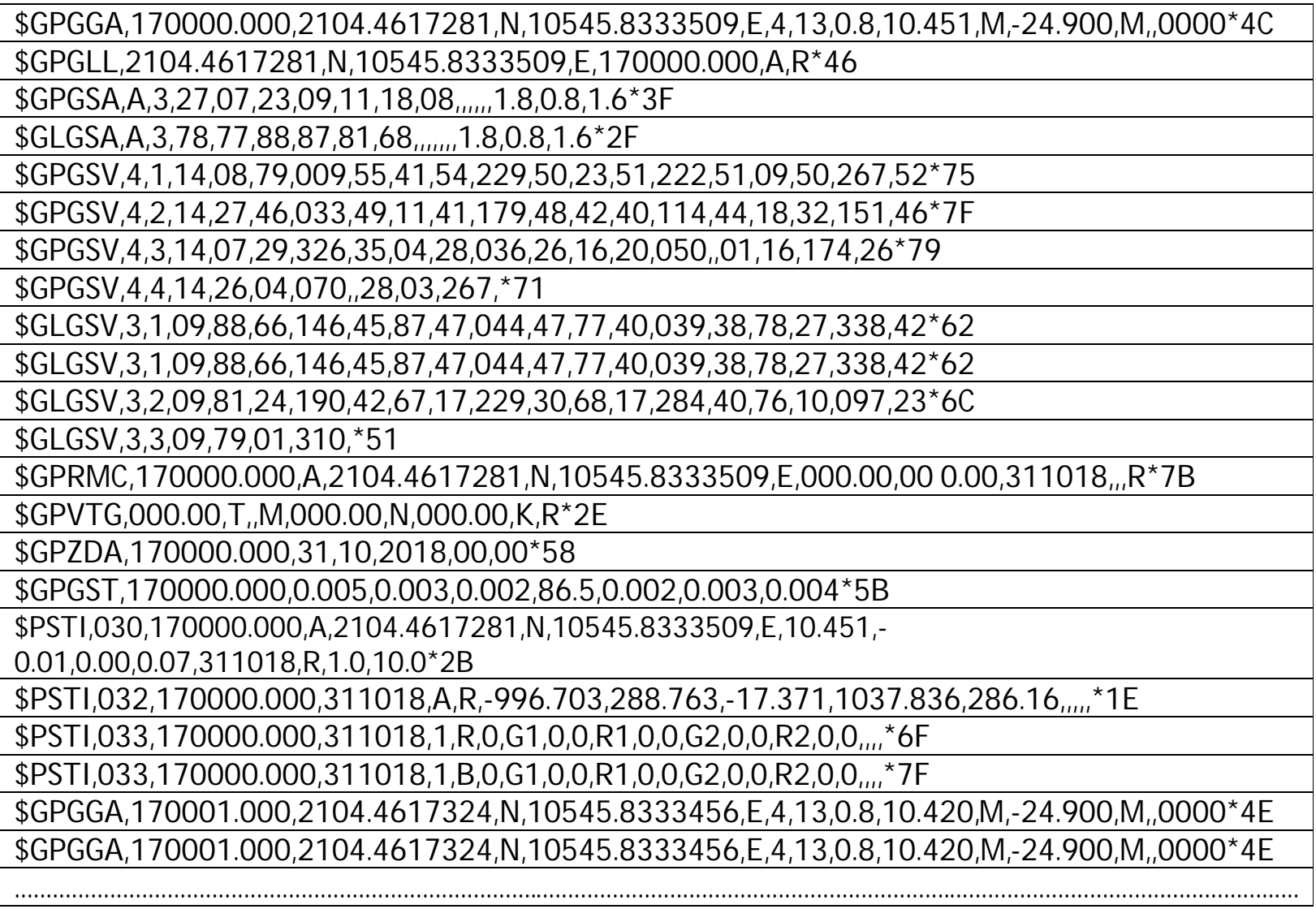

Figure 9. A section of monitoring data of An Binh high-rise building.

The data of each day is saved to a file, the measurement message collected at the monitoring station is sent to the NMEA-0183 standard format.

Figure 9 shows a piece of data collected at An Binh building monitoring station.

Monitoring is continuously carried out 24/ 7 within 3 months from $2^{\text {nd }}$ August to $5^{\text {th }}$ November 2018. Processing and analyzing data, determination on of deformation and displacement quantities, and evaluation of the stability of the observation building are carried out through the following steps:

1. Check the integrity of the messages in the GGA format in the data file.

2. Filter out messages whose coordinates have been fixed.

3. Filter out the messages which have the smallest positional uncertainties.

4. Convert the coordinates of the monitoring station to the WGS84 coordinate system.

5. Transform WGS84 coordinates to VN2000 coordinate system.
6. From the coordinates of the monitoring point in the VN2000 coordinate system, the average of which in every hour will give one position. Comparing coordinates between different time periods will determine the horizontal and vertical displacement of the monitoring points. Based on the displacement of the monitoring stations, the stability of the building will be assessed.

Results of the processing of monitored data are calculated by a self-developed software and presented in Table 2.

After processing and determining the coordinates of the monitoring station the average daily coordinates for the building is calculated (step 6) and presented in Table 3.

The displacements in Table 9 obtained during the 1-month observation period show that the differences in coordinates, distances, and height are smaller than their error, therefore, it can be concluded that An Binh building is stable without deformation during that time. 
Table 2. Results of processing of monitored data on step 4, 5 of An Binh high-rise building

\begin{tabular}{|c|c|c|c|c|c|c|}
\hline No & $\begin{array}{lll} & \mathrm{B} & \\
0 & , \quad \prime\end{array}$ & $\begin{array}{ll} & \mathrm{L} \\
\text { o } & , \quad \prime\end{array}$ & $\begin{array}{c}\mathrm{H} \\
(\mathrm{m})\end{array}$ & $\begin{array}{c}\mathrm{X} \\
(\mathrm{m})\end{array}$ & $\begin{array}{c}\mathrm{Y} \\
(\mathrm{m})\end{array}$ & $\begin{array}{c}\mathrm{h} \\
(\mathrm{m})\end{array}$ \\
\hline 1 & 21411.158440 & 1054638.154462 & 68.407 & 2330873.187 & 580572.482 & 93.469 \\
\hline 2 & 21411.158470 & 1054638.154516 & 68.410 & 2330873.188 & 580572.484 & 93.472 \\
\hline 3 & 21411.158440 & 1054638.154558 & 68.409 & 2330873.187 & 580572.485 & 93.471 \\
\hline 4 & 21411.158554 & 1054638.154456 & 68.402 & 2330873.190 & 580572.482 & 93.464 \\
\hline 5 & 21411.158434 & 1054638.154552 & 68.405 & 2330873.186 & 580572.485 & 93.467 \\
\hline 6 & 21411.158530 & 1054638.154486 & 68.409 & 2330873.189 & 580572.483 & 93.471 \\
\hline 7 & 21411.158554 & 1054638.154522 & 68.410 & 2330873.190 & 580572.484 & 93.472 \\
\hline 8 & 21411.158440 & 1054638.154468 & 68.402 & 2330873.187 & 580572.482 & 93.464 \\
\hline 9 & 21411.158422 & 1054638.154492 & 68.405 & 2330873.186 & 580572.483 & 93.467 \\
\hline 10 & 21411.158464 & 1054638.154450 & 68.407 & 2330873.187 & 580572.482 & 93.469 \\
\hline 11 & 21411.158482 & 1054638.154564 & 68.402 & 2330873.188 & 580572.485 & 93.464 \\
\hline 12 & 21411.158428 & 1054638.154528 & 68.405 & 2330873.186 & 580572.484 & 93.467 \\
\hline 13 & 21411.158566 & 1054638.154450 & 68.407 & 2330873.190 & 580572.482 & 93.469 \\
\hline 14 & 21411.158566 & 1054638.154510 & 68.402 & 2330873.190 & 580572.484 & 93.464 \\
\hline 15 & 21411.158494 & 1054638.154504 & 68.405 & 2330873.188 & 580572.483 & 93.467 \\
\hline 16 & 21411.158518 & 1054638.154450 & 68.402 & 2330873.189 & 580572.482 & 93.464 \\
\hline 17 & 21411.158536 & 1054638.154444 & 68.402 & 2330873.190 & 580572.482 & 93.464 \\
\hline 18 & 21411.158554 & 1054638.154420 & 68.403 & 2330873.190 & 580572.481 & 93.465 \\
\hline 19 & 21411.158452 & 1054638.154564 & 68.410 & 2330873.187 & 580572.485 & 93.472 \\
\hline 20 & 21411.158464 & 1054638.154516 & 68.401 & 2330873.187 & 580572.484 & 93.463 \\
\hline 21 & 21411.158446 & 1054638.154474 & 68.409 & 2330873.187 & 580572.483 & 93.471 \\
\hline 22 & 21411.158524 & 1054638.154462 & 68.408 & 2330873.189 & 580572.482 & 93.470 \\
\hline 23 & 21411.158470 & 1054638.154534 & 68.407 & 2330873.188 & 580572.484 & 93.469 \\
\hline 24 & 21411.158542 & 1054638.154570 & 68.410 & 2330873.190 & 580572.485 & 93.472 \\
\hline 25 & 21411.158548 & 1054638.154468 & 68.405 & 2330873.190 & 580572.482 & 93.467 \\
\hline 26 & 21411.158494 & 1054638.154432 & 68.408 & 2330873.188 & 580572.481 & 93.470 \\
\hline 27 & 21411.158578 & 1054638.154540 & 68.407 & 2330873.191 & 580572.485 & 93.469 \\
\hline 28 & 21411.158512 & 1054638.154474 & 68.405 & 2330873.189 & 580572.483 & 93.467 \\
\hline 29 & 21411.158500 & 1054638.154462 & 68.405 & 2330873.188 & 580572.482 & 93.467 \\
\hline 30 & 21411.158464 & 1054638.154444 & 68.402 & 2330873.187 & 580572.482 & 93.464 \\
\hline$\ldots$ & …….............. & …..................... & ............ & ........... & $\ldots \ldots \ldots$ & \\
\hline
\end{tabular}

\section{Conclusion}

This work has focused on solving the problem of continuous monitoring deformation and displacement using GNSS/ CORS technology. A diagram of the continuous monitoring system has been set up, including the CORS station system and CMSS monitoring station. The message types of the GNSS data structure have been successfully studied and decoded including NMEA format messages sent from the host monitoring station to the server of the CORS station.
A GNSS data transmission system has been designed to develop both hardware and software that can in real time, continuously and automatically monitor deformation and displacement of construction works. The developed system automatically works well, stably, and guarantees instantaneous transmission of data from the monitoring station to the host computer.

GNSS data processing software designed and developed allows for processing data and immediately determining the deformation and displacement of construction works. The system 
Table 3. The displacements of An Binh building during 1 month

\begin{tabular}{|c|c|c|c|c|c|c|c|}
\hline $\begin{array}{c}\text { Monitoring } \\
\text { time }\end{array}$ & $\begin{array}{c}\mathrm{X} \\
(\mathrm{m})\end{array}$ & $\underset{(\mathrm{m})}{\mathrm{Y}}$ & $\underset{(\mathrm{m})}{\mathrm{H}}$ & $\begin{array}{c}\mathrm{dX} \\
(\mathrm{mm})\end{array}$ & $\underset{(\mathrm{mm})}{\mathrm{dY}}$ & $\underset{(\mathrm{mm})}{\mathrm{dP}}$ & $\underset{(\mathrm{mm})}{\mathrm{dh}}$ \\
\hline $2 / 8 / 2018$ & 2330873.189 & 580572.484 & 93.471 & & & & \\
\hline & & & & 2 & 3 & 3.6 & -3 \\
\hline $3 / 8 / 2018$ & 2330873.191 & 580572.487 & 93.468 & & & & \\
\hline & & & & 4 & 2 & 4.5 & 3 \\
\hline $4 / 8 / 2018$ & 2330873.195 & 580572.489 & 93.471 & & & & \\
\hline $5 / 8 / 2018$ & 2330873103 & 580572485 & 93466 & -2 & -4 & 4.5 & -5 \\
\hline & & & & -4 & 3 & 5.0 & 4 \\
\hline $6 / 8 / 2018$ & 2330873.189 & 580572.488 & 93.47 & & & & \\
\hline & & & & 1 & -4 & 4.1 & -2 \\
\hline $7 / 8 / 2018$ & 2330873.19 & 580572.484 & 93.468 & & & & \\
\hline $8 / 8 / 2018$ & 2330873185 & 58057248 & 03.462 & -5 & -4 & 6.4 & -6 \\
\hline & & & Ju.Tuz & 2 & 4 & 4.5 & -1 \\
\hline $9 / 8 / 2018$ & 2330873.187 & 580572.484 & 93.461 & & & & \\
\hline & & & & -1 & -3 & 3.2 & 2 \\
\hline $10 / 8 / 2018$ & 2330873.186 & 580572.481 & 93.463 & & & & \\
\hline & & & & 5 & 7 & 8.6 & 4 \\
\hline $11 / 8 / 2018$ & 2330873.191 & 580572.488 & 93.467 & -2 & -1 & 2) & 3 \\
\hline $12 / 8 / 2018$ & 2330873.189 & 580572.487 & 93.47 & & & & \\
\hline & & & & 3 & -3 & 4.2 & 1 \\
\hline $13 / 8 / 2018$ & 2330873.192 & 580572.484 & 93.471 & & & & \\
\hline $14 / 8 / 2018$ & 2220077 & & & 2 & 2 & 2.8 & -5 \\
\hline $14 / 0 / 2010$ & $25000 \%$ & 580 & 90.400 & -4 & -1 & 41 & 1 \\
\hline $15 / 8 / 2018$ & 2330873.19 & 580572.485 & 93.467 & & & & \\
\hline & & & & 2 & 4 & 4.5 & 2 \\
\hline $16 / 8 / 2018$ & 2330873.192 & 580572.489 & 93.469 & & & & \\
\hline & & & & 3 & -4 & 5.0 & -2 \\
\hline $1 / / 8 / 2018$ & $23308 / 3.195$ & $5805 / 2.485$ & $93.40 /$ & -4 & 3 & 50 & 1 \\
\hline $18 / 8 / 2018$ & 2330873.191 & 580572.482 & 93.466 & & - & 0.0 & 1 \\
\hline & & & & -5 & 2 & 5.4 & 5 \\
\hline $19 / 8 / 2018$ & 2330873.186 & 580572.484 & 93.471 & & & & \\
\hline $30 / 8 / 2018$ & 232087310 & 580572187 & 02,160 & 4 & 3 & 5.0 & -2 \\
\hline $20 / 8 / 2018$ & $23308 / 3.19$ & $5805 / 2.48 /$ & 93.469 & ? & 1 & 22 & 1 \\
\hline $21 / 8 / 2018$ & 2330873.192 & 580572.488 & 93.473 & 2 & 1 & & \pm \\
\hline & & & & -1 & -4 & 4.1 & -1 \\
\hline $22 / 8 / 2018$ & 2330873.191 & 580572.484 & 93.472 & & & & \\
\hline & & & & -2 & 1 & 2.2 & -2 \\
\hline $23 / 8 / 2018$ & 2330873.189 & 580572.485 & 93.47 & & & & \\
\hline & & & & 4 & 3 & 5.0 & 5 \\
\hline $24 / 8 / 2018$ & 2330873.193 & 580572.488 & 93.475 & & & & \\
\hline $25 /$ & $22^{\prime}+3$ & & 7 & 2 & -3 & 3.6 & -5 \\
\hline & & & & -6 & -3 & 6.7 & 1 \\
\hline $26 / 8 / 2018$ & 2330873.189 & 580572.482 & 93.471 & & & & \\
\hline & & & & 6 & 4 & 7.2 & 2 \\
\hline $27 / 8 / 2018$ & 2330873.195 & 580572.486 & 93.473 & & & & \\
\hline & & & & -3 & -2 & 3.6 & -2 \\
\hline 29/8/2018 & 2330873.192 & 580572.484 & 93.471 & & & & \\
\hline $20 / 8$ & & & & -1 & 3 & 3.2 & 6 \\
\hline & & & & -2 & -4 & 45 & -5 \\
\hline $30 / 8 / 2018$ & 2330873.189 & 580572.483 & 93.472 & & & & \\
\hline & & & & 4 & 2 & 4.5 & -4 \\
\hline $31 / 8 / 2018$ & 2330873.193 & 580572.485 & 93.468 & & & & \\
\hline
\end{tabular}


of monitoring stations has been studied, developed, and tested by specialized equipment. It works well, stably, continuously and ensuresthe required accuracy to monitor deformation and displacement of the construction works up to 3 $\mathrm{mm}$ in horizontal and $5 \mathrm{~mm}$ in height.

\section{Acknowledgements}

This research was financially supported by the Hanoi People's Committee (grant number 01C-4/ 08-2016-3) and the Hanoi Department of Science and Technology.

\section{References}

Bochen Zhang, Xiaoli Ding, Charles Werner, Kai Tan, Bin Zhang, Mi Jiang, Jingwen Zhao, Youlin $\mathrm{Xu}, 2018$. Dynamic displacement monitoring of long-span bridges with a microwave radar interferometer. ISPRS Journal of Photogrammetry and Remote Sensing, 138, 252-264.

Deng hui Wang, Xiaolin Meng, Chengfa Gao, Shuguo Pan, Qusen Chen, 2017. Multipath extraction and mitigation for bridge deformation monitoring using a singledifference model. Advances in Space Research, 60, Issue 12, 2882-2895.

Hepi Hapsari Handayani, Yuwono, Taufik M, 2015. Preliminary study of bridge deformation monitoring using GPS and CRP (case study: Suramadu Bridge). Procedia Environmental Sciences, 24, 266-276.

Jiayong Yu, Xiaolin Meng, Xudong Shao, Banfu Yan, Lei Yang, 2014. Identification of dynamic displacements and modal frequencies of a medium-span suspension bridge using multimode GNSS processing. Engineering Structures, 81, 432-443.

N. Quesada-Olmo, M.J. Jimenez-Martinez, M. Farjas-Abadia, 2018. Real-time high-rise building monitoring system using global navigation satellite system technology. Measurement, 123, 115-124.

Ruijie Xi, WeipingJiang, Xiaolin Meng, Hua Chen, Qusen Chen, 2018. Bridge monitoring using BDS-RTK and GPS-RTK techniques. Measurement, 120, 128-139.
Wan Abdul Aziz Wan Mohd Akib, Shu Kian Kok, Zulkarnaini Mat Amin, 2012. High Rise Building Deformation Monitoring With GPS. Department of Geomatic Enginnering Faculty of Geoinformation Science \& Engineering University Teknologi Malaysia, 81310 Skudai, Johor Malaysia.

Kai Shi, Ming $\mathrm{Xu}$, Haoxia Jin, Tong Qiao, XueYang, Ning Zheng, JianXu, Kim-Kwang Raymond Choo, 2017. A novel file carving algorithm for National Marine Electronics Association (NMEA) logs in GPS forensics. Digital Investigation, 23, 11-21.

Pham Cong Khai, Le Van Canh, Nguyen Quoc Long, Nguyen Viet Nghia, Pham Van Chung, Vo Ngoc Dung, Nguyen Gia Trong, Le Duc Tinh, Nguyen Viet Ha, Nguyen Van Sang, 2019. Research on technology applycation continous monitoring of displacement and deformation of works in erea of Hanoi City. Final report of Science and Technology project of city level. Grant number 01C04/ 08-2016-3. Hanoi Department of Science and Technology.

Pham Cong Khai, Nguyen Van Hai, (2020). Investigation and design of monitoring systems in real time landslides at Xekaman 3 hydropower plant. Journal of Mining and Earth Sciences 61 (1), 11-20. 